\title{
EARTHQUAKE CYCLE DEFORMATION AT THE BALLENAS TRANSFORM, GULF OF CALIFORNIA, MEXICO, FROM INSAR AND GPS MEASUREMENTS
}

\author{
Christina Plattner ${ }^{(1)}$, Heresh Fattahi ${ }^{(2)}$, Rocco Malservisi ${ }^{(3)}$, Falk Amelung ${ }^{(2)}$, Alessandro \\ Verdecchia $^{(1)}$, Timothy H. Dixon ${ }^{(3)}$ \\ (1) Dept. of Earth and Environmental Sciences, Ludwig-Maximilians Universitaet Muenchen, \\ Luisenstrasse 37,80333 Muenchen, Germany,Email: christina.plattner@iaag.geo.uni-muenchen.de; \\ alessandro.verdecchia@iaag.geo.uni-muenchen.de \\ (2) University of Miami, Rosenstiel School of Marine and Atmospheric Sciences, 4600 Rickenbacker \\ Cswy, Miami,FL, 33149,USA,Email:hfattahi@rsmas.miami.edu,famelung@rsmas.miami.edu \\ (3) University of South Florida, School of Geosciences, 4202 E. Fowler Avenue, NES 107, Tampa, FL \\ 33620-5550,USA,Email: rocco@usf.edu,thd@usf.edu
}

\begin{abstract}
We study crustal deformation across the Ballenas marine channel, Gulf of California, Mexico using InSAR and campaign GPS data. Interseismic velocities are calculated by time-series analysis spanning five years of data. Displacements from the August $3^{\text {rd }} 2009$ Mw 6.9 earthquake are calculated by differencing the most recent observations before and after the event. To estimate the offset across the marine channel we calibrate the InSAR velocity and displacement fields using the corresponding GPS data. Unfortunately, the InSAR interseismic velocity field is affected by residual tropospheric delay. We interpret the GPS interseismic and the GPS and InSAR coseismic deformation data using dislocation modeling and compare the fault kinematics during these periods of the earthquake cycle.
\end{abstract}

\section{INTRODUCTION}

The Gulf of California, Mexico, accommodates about 90\% of the North America - Pacific plate relative motion, equivalent to $\sim 43-47 \mathrm{~mm} / \mathrm{yr}[1,2,3]$. The transtensional fault system provides a unique opportunity to study deformation associated with the transition of a continental strike-slip fault (the San Andreas fault) to seafloor spreading (East Pacific Rise) $[4,5]$.

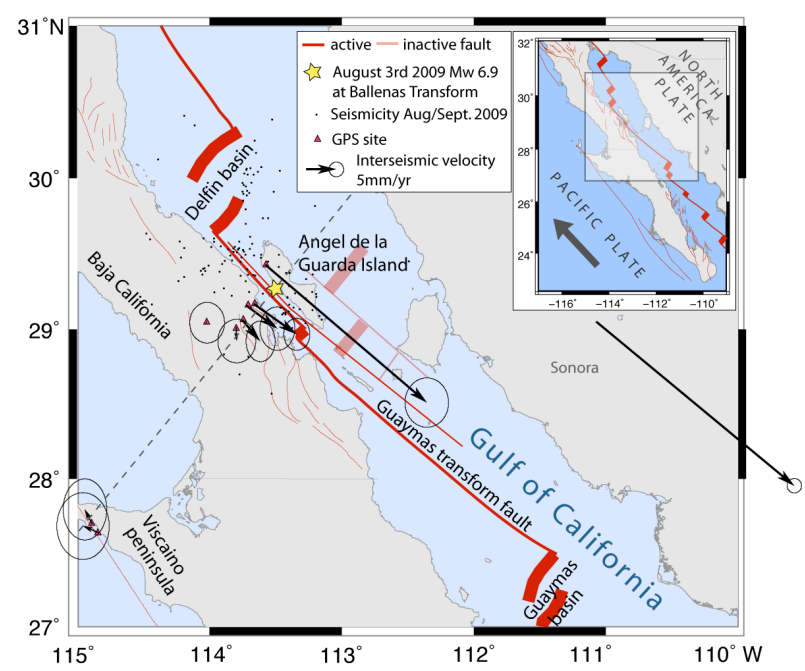

Figure 1: Ballenas Transform, Gulf of California, Mexico. Local campaign GPS network and permanent station in Sonora show interseismic velocities (June 2004 - May 2009) in stable Baja California reference frame (Plattner et al., 2007 [3]). Dashed profile is used for interseismic strain accumulation modeling. Figure modified from [12]. 
Due to the submarine setting, however, the present-day fault kinematics was mainly constrained by seismicity data $[6,7]$. The Ballenas transform (Fig. 1) is one of the few fault segments in the Gulf that come sufficiently close to peninsular Baja California to allow the application of space-geodetic data for crustal deformation studies. Moreover, the fault is located within a 10 - $20 \mathrm{~km}$ wide marine channel, bordered to the western side by Angel de la Guarda Island. Here we present space-geodetic data that recorded $\sim$ five years of interseismic crustal deformation across the Ballenas Transform and displacements from the August $3^{\text {rd }} 2009$ $M_{w} 6.9$ earthquake, its foreshocks and aftershocks [8]. Using dislocation modeling we analyze and compare the fault kinematics during these different periods of the earthquake cycle.

\section{DATA ANALYSIS}

\subsection{GPS}

In 2004 we installed a campaign Global Positioning System (GPS) network across the Ballenas channel (Fig. 1) to monitor the interseismic motions. To constrain the farfield velocities we installed two additional campaign stations in western Baja California and retrieved data from a permanent station in mainland Mexico (HER2 from Mexican National geodetic network RGNAINEGI). Only few months after the third campaign measurements, the $\mathrm{M}_{\mathrm{w}} 6.9$ earthquake occurred along the Ballenas Transform [8]. To measure the displacements from this event we reoccupied the entire GPS network in September 2009.

The GPS data are processed using GIPSY/OASIS II, Release 6.2 software and non-fiducial satellite orbit and clock files provided by the Jet Propulsion Laboratory
[9]. The analysis followed [10], but the daily solutions were aligned to ITRF08 [11].

From the daily position estimates and uncertainties from June 2004 to May 2009 we calculate interseismic velocities by linear least squares regression. We project the velocities into stable Baja California reference frame [3, 12] (Fig. 1). Coseismic displacements are calculated by differencing the averaged position measurements made in May and September 2009 [12].

\subsection{InSAR}

We acquired Synthetic Aperture Radar (InSAR) data from Envisat satellite descending tracks 270 and 499 and ascending track 034, with observations between 2003 and October 2010. We use the JPL/Caltech ROI_PAC software [13] for processing interferograms. Phase due to topography is removed using Shuttle Radar Topography Mission (SRTM) data. The interferograms are unwrapped using the statistical-cost network-flow algorithm for phase unwrapping (SNAPHU) [14].

For calculating interseismic velocities, we select all interferograms from descending track 499 with images from 2003 to May 2009 (the ascending track does not have enough data). We invert the network of interferograms for the phase history at each epoch relative to the first [15]. We correct for the local oscillator drift of the ASAR instrument in the time domain [16, 17], for topographic residuals [18], and for the stratified tropospheric delay [19] using the ERAInterim global atmospheric reanalysis model of the European Center for Medium-Range Weather Forecasts [20]. Due to the unknown phase jumps between the Baja peninsula and Angel de la Guarda Island we first reference all the interferograms to a coherent pixel on the peninsula and conduct the time-series analysis using the approach explained above and then repeat the time- 
series analysis with a different reference point on the island. We solve for the offset between the InSAR velocity field on the island and the peninsula by minimizing the misfit to the GPS velocities, using the fault-parallel component of the InSAR and GPS signal.

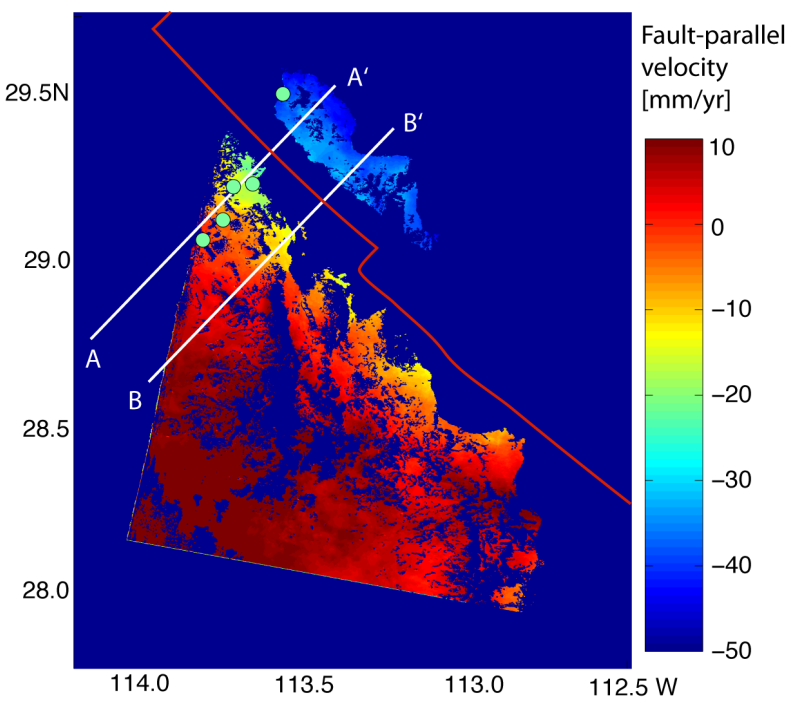

Figure 2: Interseismic velocity field from InSAR after calibration to GPS data. Green dots show location of GPS stations. Data along 20 parallel profiles between $A A^{\prime}$ and $B B$ ' are shown in Fig. 3.

Coseismic displacements are calculated by differential InSAR using the most recent acquisitions before and after the earthquake [12]. For deformation analysis we choose only one interferogram from each track that has the highest coherence and little noise. Due to sparse data for the ascending track the most suitable interferogram has a time-span of more than five years. We correct this interferogram for interseismic strain accumulation from the Ballenas Transform using our best-fitting model that we present in the next section [12]. We calibrate all three interferograms to the GPS displacemenet data to solve for the offset between the island and the peninsula. Here, we use the east, north, and up components of the GPS displacement vector to calculate the equivalent line-of-sight change [12].

\section{INTERPRETATION AND MODELING}

\subsection{Interseismic velocity and strain accumulation modeling}

Because rigid rotation of the Baja California microplate is subtracted from the GPS velocity field, any remaining motion within the microplate indicates internal deformation (Fig. 1). Significant internal deformation is observed at sites adjacent to the Ballenas channel, where the site velocities point in North America - Baja California relative plate motion direction, and rates increase as the distance to the fault decreases (maximum rate at peninsula is $8.8 \pm 1.4 \mathrm{~mm} / \mathrm{yr}$ ). On the opposite site of the Ballenas fault, our GPS station on Angel de la Guarda Island shows a large relative motion with respect to Baja California $(35.7 \pm 2.3 \mathrm{~mm} / \mathrm{yr})$, but significantly lower than that at site HER2 on mainland Mexico (43.3 \pm 0.7$)$. The observed velocity field is consistent with strain accumulation on a locked, rightlateral strike-slip fault within the Ballenas channel.

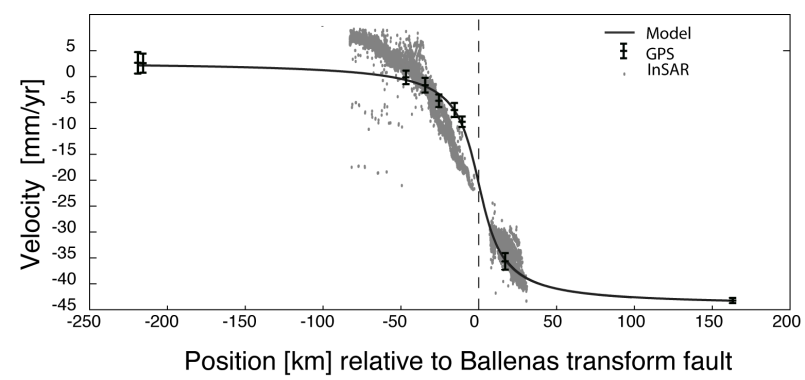

Figure 3: GPS interseismic velocities (in stable Baja California reference frame) projected in fault-parallel direction and best-fitting strain accumulation model (Savage and Burford, 1973). Gray dots show InSAR data from profiles across the fault, with the InSAR lineof-sight data projected into fault-parallel direction. Misfit of InSAR to GPS data on Baja California (left side) is explained by residual tropospheric delay after correction.

The InSAR velocity field (also set into stable Baja California reference frame) shows a fault-perpendicular gradient in motion across Baja California peninsula and Angel de la Guarda Island (Fig. 2), which in general 
corresponds to the deformation pattern seen from GPS. We extracted data along 20 profiles in between AA' and BB' (Fig. 2) and compared the velocity gradient to that of the GPS data (Fig. 3). The InSAR data shows a much greater gradient than the GPS. An explanation for this pattern is residuals in the tropospheric delay resulting from the low resolution of atmospheric models in this area. Therefore we do not interpret the InSAR velocities and limit our interseismic strain accumulation modeling to fit the GPS data.

We model interseismic strain accumulation along a profile across the Ballenas channel, oriented perpendicular to the fault trace (Fig. 1). We project the location of GPS stations onto the profile and project the GPS horizontal velocities in the fault-parallel direction (Fig. 3). To fit the data we use a screw dislocation model in an elastic half space [21]. The model solves for the fault slip rate, fault locking depth, the fault position and a constant velocity offset to project the velocity data into a symmetric far-field velocity reference frame. To find the best fitting model parameters, we minimize the weighted sum of squares of residuals. Our best-fitting model shows a good fit to the GPS data (Fig. 3) with a reduced $\chi^{2}$-mistfit of 0.35 $\mathrm{mm}$. The inverted fault slip rate is $47.3 \pm 0.8 \mathrm{~mm} / \mathrm{yr}$ and our best-fitting fault locking depth is $11.4 \pm 1.1 \mathrm{~km}$. The fault is located within the Ballenas channel, passing through $-113.55^{\circ} \mathrm{E}, 29.25^{\circ} \mathrm{N}$.

\subsection{Coseismic displacements and fault rupture} surface modeling

For the modeling procedure, the InSAR data is gridded with $\mathrm{a} \sim 2 \mathrm{~km}$ resolution. We test different assumptions on the weighting of the InSAR and GPS data, until an optimal model solution with a relative low root mean square (rms) is obtained [12]. The coseismic displacement model is a rectangular dislocation with uniform slip in a homogenous, isotropic, elastic halfspace [22]. Simultaneously with the deformation source, we solve for phase ramps for each averaged interferogram representing long-wavelength tropospheric delay variations [16]. The best-fitting model is found by inversion of the displacement fields from the three interferograms and of the GPS data, using a Monte Carlo-type simulated annealing algorithm [23].

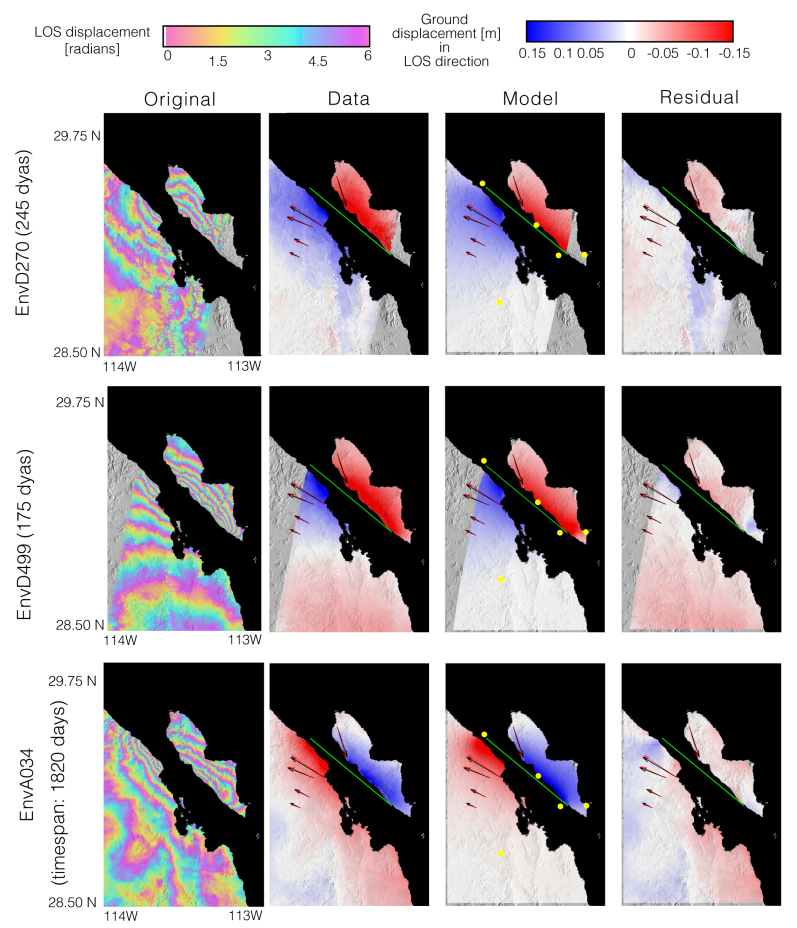

Figure 4: Original wrapped and unwrapped (after calibration to fit GPS data), modeled, and residual displacement field for the coseismic period spanning the August $3^{\text {rd }} 2009$ earthquake. Black arrows are GPS observed data, red arrows are from model. Yellow dots show $>M_{w} 5$ foreshocks and aftershocks (Castro et al., [10]). Figure modified from [12].

Our preferred uniform slip model [12] shows a good fit to the data (Fig. 4). The model fault is located within the Ballenas channel (centered at $29.23^{\circ} \mathrm{N},-113.48^{\circ} \mathrm{E}$ ) and oriented parallel to the Ballenas transform (strike $=$ $310^{\circ}$ ). The model fault extends from the southeastern 
margin of the Ballenas basin $65 \mathrm{~km}$ northwest towards the southwestern edge of the Delfin basin. The width and depth of the fault plane of each $14 \mathrm{~km}$ imply surface rupture of the vertically orientated fault plane (dip = $90^{\circ}$ ). The uniform slip model has a strike-slip offset of $1.3 \mathrm{~m}$. We also tested for dip-slip component but find that the model fit does not improve significantly. We calculate the best-fitting slip distribution (strike-slip only) on the fault plane, extending the fault plane to 100 x $20 \mathrm{~km}$ and diving it into $2 \times 2 \mathrm{~km}$ fault patches. Incrementally we increase the surface roughness, until the misfit-decrease converges [24]. The presented slipdistribution is rather simple, showing an elliptical rupture area with a single slip-maximum reaching $1.4 \mathrm{~m}$ at a depth of $8-10 \mathrm{~km}$ (Fig. 5). The geodetic moment of our distributed slip model is $3.66 \times 10^{19} \mathrm{Nm}$, which is $\sim 26 \%$ greater the sum of the main, fore-, and major aftershocks $\left(2.90 \times 10^{19} \mathrm{Nm}\right.$ derived from Global CMT catalog). This difference most likely reflects postseismic deformation observed by the geodetic data that may be associated with aseismic transient deformation as afterslip, viscous, or poro-elastic deformation.

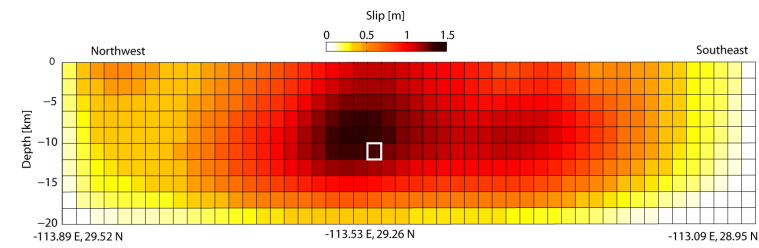

Figure 3: Slip distribution along fault plane. White box marks slip maximum of $1.4 \mathrm{~m}$. Figure modified from [12].

\section{DISCUSSION AND CONCLUSION}

We compare the interseismic fault rate $(47.3 \pm 0.8$ $\mathrm{mm} / \mathrm{yr}$ ) to the geodetic rigid plate relative motion between Baja California microplate and North America at this location $(44.9 \pm 3.4 \mathrm{~mm} / \mathrm{yr})[3]$ and conclude that fault east of Angel de la Guarda island are essentially inactive, as previously suggested [25]. The interseismic fault locking depth $(11.4 \pm 1.1 \mathrm{~km})$ and the earthquake rupture width $(14 \mathrm{~km})$ are within estimates of the base of seismicity along transform faults in the Gulf. The fault location from both models, and the orientation of the coseismic rupture surface agree with the epicentral location of the August $3^{\text {rd }} 2009$ earthquake and the fault interpretation from multibeam bathymetry data (Peter Lonsdale, personal communication) [12]. The coseismic model fault agrees also well with the location of the foreshock and major aftershocks [8]. Absence of extensional kinematics during the earthquake is in agreement with the seismic moment tensor and the transform and ridge kinematics found from analysis of seismicity data $[7,8,12]$.

\section{FUTURE WORK}

We presented space-geodetic data from GPS and InSAR showing the surface deformation from interseismic strain accumulation and coseismic stress release from the August $3^{\text {rd }} 2009 \mathrm{Mw} 6.9$ earthquake at the Ballenas transform, Gulf of California. We anticipate an improved correction of tropospheric delay in the InSAR interseismic velocity field to allow us to study if and how the interseismic strain accumulation pattern varies along-strike the Ballenas Transform towards the extensional basins in the Gulf of California. Furthermore, we anticipate analysis of postseismic data from GPS and InSAR to estimate viscous relaxation in the lower crustal and upper mantle.

\section{REFERENCES}

1. DeMets, C., Gordon, R. G, Argus, D. F. \& Stein, S. (1994). Effect of Recent Revisions to the Geomagnetic Reversal Time-Scale on 
Estimates of Current Plate Motions, Geophys. Res. Lett., 21, 2191, doi:10.1029/94GL02118.

2. DeMets, C., Gordon, R. G., Argus, D. F. \& Stein, S. (1990). Current plate motions, Geophys. J. Int., 101, 425-478, doi:10.1111/j.1365-246X.1990.tb06579.x.

3. Plattner, C., Malservisi, R. \& Dixon, T.H. (2007). New constrains. Geophys. J. Int., 285(11), 123-126.

4. McQuarrie, N. \& Wernicke, B. P. (2005). An animated tectonic reconstruction of southwestern North America since $36 \mathrm{Ma}$, Geosphere, 1, 147-172.

5. Plattner, C., Malservisi, R., Furlong, K. P. \& Govers, R. (2010). Development of the Eastern California Shear Zone - Walker Lane belt: the effects of microplate motion and pre-existing weakness in the Basin and Range, Tectonophysics, $\quad \mathbf{4 8 5}, \quad$ 78-84, doi:10.1016/j.tecto.2009.11.021.

6. Goff, J.A., Bergman, E. A. \& Solomon, S. C. (1987). Earthquake source mechanism and transform fault tectonics in the Gulf of California, J. Geophys. Res. 92, 10485-10510, doi:10.1029/JB092iB10p10485.

7. Sumy, D.F., Gaherty, J. B., Kim, W-Y., Diehl, T. \& Collins, J. A. The mechanisms of earthquakes and faulting in the Southern Gulf of California, Bull. Seism. Soc. Am., 103(1), 487-506, doi:10.1785/0120120080.

8. Castro, R.R., Valdes-Gonzalez, C.m Shearer, P.m Wong, V., Astiz, L., Vernon, F., PerezVertti, A. \& Mendoza, A. (2011). The 3 August Mw 6.9 Canal de Ballenas Region,
Gulf of California, Earthquake and its aftershocks, Bull. Seism. Soc. Am., 101(3), 929-939, doi:10.1785/0120100154.

9. Zumberge, J.F., Heflin, M. B., Jefferson, D. J., Watkins, M.M. \& Webb, F. H. (1997). Precise point positioning for the efficient and robust analysis of GPS data from large networks, $J$. Geophys. Res., 102(3), 5005-5017, doi:10.1029/96JB03860.

10. Sella, G.F., Dixon, T. H. \& Mao, A. (2002). REVEL: A model for recent plate velocities from space geodesy, J. Geophys. Res., 107(4), doi:10.1029/2000JB000033.

11. Altamimi, Z., Collilieux, X. \& Metivier, L. (2011). ITRF2008: an improved solution of the international terrestrial reference frame. $J$. Geodesy, 85(8), 457-473, doi:10.1007/s00190011-0444-4.

12. Plattner, C., Malservisi, R., Amelung, F., Dixon, T.H., Hackl, M., Verdecchia, A., Lonsdale, P., Suarez-Vidal, F. \& GonzalezGarcia, J. (2015). Interseismic strain accumulation and coseismic rupture from the $2009 \mathrm{M}_{\mathrm{w}} 6.9$ earthquake at the Ballenas Transform, Gulf of California, Mexico, from GPS and InSAR measurements. J. Geophys. Res., in review.

13. Rosen, P.A., Hensley, S., Peltzer, G. \& Simonsm M. (2004). Update repeat orbit interferometry package released, EOS, Trans. Am. geophys. Un., 85, 47.

14. Chen, C. W. \& Zebker, H.A. (2001). Twodimensional phase unwrapping with use of statistical models for cost functions in 
nonlinear optimization, J. Opt. Soc. Am.,18(2), 338-351, doi:10.1364/JOSAA.18.000338.

15. Berardino, P., Fornaro, G., Lanari, R., Member, S., \& Sansosti, E. (2002). A New Algorithm for Surface Deformation Monitoring Based on Small Baseline Differential SAR Interferograms. IEEE Transactions on Geoscience and Remote Sensing, 40(11), 2375-2383.

16. Fattahi, H. \& Amelung, F. (2014). InSAR uncertainty due to orbital errors, Geophy J. Int, 199(1), 549-560, doi:10.1093/gji/ggu276.

17. Marinkovic, P., \& Larsen, Y. (2013). Consequences of long-term ASAR local oscillator frequency decay-An empirical study of 10 years of data. In Living Planet Symp., Edinburgh, UK.

18. Fattahi, H., \& Amelung, F. (2013). DEM Error Correction in InSAR Time Series. IEEE Transactions on Geoscience and Remote Sensing, 51(7), 4249-4259. doi:10.1109/tgrs.2012.2227761

19. Jolivet, R., Agram, P. S., Lin, N. Y., Simons, M., Doin, M., Peltzer, G., \& Li, Z. (2014). Improving InSAR geodesy using Global Atmospheric Models. J. Geophys. Res.: 119, 2324-2341. doi:10.1002/2013JB010588.

20. Dee, D. P., Uppala, S.M., Simmons, A.J., Berrisford, P., Poli, P., Kobayashi, S., ... Vitart, F. (2011). The ERA-Interim reanalysis: configuration and performance of the data assimilation system. Quarterly Journal of the Royal Meteorological Society, 137(656), 553597. doi:10.1002/qj.828.
21. Savage, J.C., and Burford, R.O. (1973). Geodetic determination of relative motion in central California, J. Geophys. Res., 78(5), 832-845, doi:10.1029/JB078i005p00832.

22. Okada, Y. (1985). Surface deformation due to shear and tensile faults in a half-space, Bull. Seism. Soc. Am., 75(4), 1135-1154.

23. Cervelli, P., Murray, M. H., Segall, P., Aoki, Y., \& Kato, T. (2001). Estimating source parameters from deformation data, with an application to the March 1997 earthquake swarm off the Izu Peninsula, Japan, $J$. Geophys. Res., 106, B6, 11217-11237, doi:10.1029/2000JB900399.

24. Jonsson, S., Zebker, H.A., Segall, P. \& Amelung, F. (2002). Fault slip distribution of the $1999 \mathrm{Mw} 7.1$ Hector Mine, California, Earthquake, estimated from Satellite Radar and GPS Measurements, Bull. Seism. Soc. Am., 92 (4), 1377-1389, doi:10.1785/0120000922.

25. Bennett, S.E.K, Oskin, M. E. \& Iriondo, A. (2013). Transtensional Rifting in the ProtoGulf of California, near Bahia Kino, Sonora, Mexico, Geol. Soc. Am. Bull., 125(11/12), 1752-1782, doi:10.1130/B30676.1. 